\title{
O FIM DA PRISÃO DISCIPLINAR ADMINISTRATIVA
}

\section{ARTIGO ORIGINAL}

BARBOSA, Higor Eduardo Abreu ${ }^{1}$

FURLAN, Fernando Palma Pimenta ${ }^{2}$

BARBOSA, Higor Eduardo Abreu. FURLAN, Fernando Palma Pimenta. O fim da prisão disciplinar administrativa. Revista Científica Multidisciplinar Núcleo do Conhecimento. Ano 05, Ed. 10, Vol. 08, pp. 05-22. Outubro de 2020. ISSN: 24480959, Link de acesso: https://www.nucleodoconhecimento.com.br/lei/prisaodisciplinar

\section{RESUMO}

O presente trabalho busca abordar a pena militar de prisão disciplinar na forma administrativa e sua alteração que culminou em pôr fim a esse tipo de punição em âmbito nacional a todos os militares Estaduais com a Lei 13.967 de 2019. A prisão disciplinar administrativa sempre foi um assunto controverso devido a não estar de acordo com os princípios constitucionais que regem as normas de direito, que afirmam que não há extinção da liberdade do indivíduo antes do trânsito em julgado, entretanto dá a possibilidade de penalidade de prisão disciplinar por transgressão administrativa dos militares. Tem como metodologia a revisão de literatura, com delineamento bibliográfico. O trabalho busca analisar como esta medida afeta a carreira militar e seu bem-estar, pois possibilita excessos por parte superior da hierarquia em punições descabidas. Ficou evidenciado que as legislações a respeito do regulamento disciplinar dos militares estaduais já vinham, a algum tempo, se adequando quanto a

\footnotetext{
${ }^{1}$ Acadêmico do $10^{\circ}$ período do curso de direito na UnirG - Universidade de Gurupi. ${ }^{2}$ Orientador. Mestrado em andamento em Direito. Especialização em Direito Civil E Processo Civil. Especialização em Supervisão e orientação educacional. Graduação em Direito.
} 
temática prisão disciplinar, antes mesmo da Lei em 2019 promover a alteração, exemplos são a Polícia Militar do Estado de Minas Gerais como a Polícia Militar do Estado da Paraíba abolindo-a de suas rotinas. Portanto, o artigo traz sugestões de penalidades alternativas, que já estão atuantes em determinadas instituições militares, partindo do pensamento de propor arrependimento ao transgressor, bem como punilo de acordo com a proporcionalidade do princípio da dignidade da pessoa humana.

Palavras-chave: Prisão disciplinar, sanção administrativa, pena militar, lei 13.967, Direito Penal Militar.

\section{INTRODUÇÃO}

Foi sancionada no dia 26 de dezembro de 2019 a Lei 13.967, que extinguiu a pena de prisão disciplinar para as polícias militares e os corpos de bombeiros militares dos Estados, dos Territórios e do Distrito Federal, e dá outras providências (BRASIL, 2019). Este ato alterou a redação do Decreto-lei 667 de 1969, que trata da reorganização do Corpo de Bombeiros e Polícia Militar dos Estados (BRASIL, 1969).

A execução desta lei vem a partir do pressuposto de valorização dos profissionais da Polícia Militar e Bombeiro. Esta alteração propõe o dever de respeitar a dignidade da pessoa humana, a legalidade, a presunção da inocência, o devido processo legal, o contraditório e a ampla defesa, a razoabilidade e proporcionalidade e a vedação de medida privativa e restritiva de liberdade.

O Decreto 667/1969 (BRASIL, 1969) foi editado ainda durante o período do Regime Militar e, como argumento, os editores do projeto afirmam: "No entanto, 25 anos depois, a cidadania ainda não chegou para os policiais e bombeiros militares" - PL 7645/2014 (CÂMARA LEGISLATIVA FEDERAL, 2014). A lei, a partir da data de promulgação, entrou em vigor, estabelecendo que a partir daquela data estará vedada penas privativas ou restritivas de liberdade, enquanto os Estados e Distrito Federal têm doze meses para regulamentar e implantar um Código de Ética e Disciplina para orientar seus Militares. 
Por outro lado, Rocha (2020) afirma que a valorização dos Policiais Militares e Bombeiros Militares não passa, necessariamente, pelo fim da prisão em função de transgressões, trazendo à luz diferença entre civis e militares, cuja segunda categoria tem bases fortemente pautadas em hierarquia e disciplina, dando importância ao cumprimento de sua missão institucional em termos de abrangência e comprometimento mais rígidos. Em que, se servidores civis se responsabilizam pelo seu empenho em prol de uma execução que atribua o bem estar a uma coletividade dependente de seus serviços, os militares também o fazem.

No entanto, a missão é sobreposta adjunto com o "risco da própria vida". Colocar a própria vida em risco em prol do bem de outros é um diferencial bastante significativo na esfera atributiva a essas duas classes de servidores mencionadas e a principal razão para a reformulação dos regimes administrativos disciplinares.

Portanto, este artigo pretende abordar, de maneira exploratória e com cunho bibliográfico, através da literatura de doutrinas e pesquisas, e documental, a partir de jurisprudências (GIL, 2008), quais os possíveis efeitos da nova Lei 13.967 no corpo militar e o que isso representa para este público.

\section{DIREITO ADMINISTRATIVO DISCIPLINAR}

Prisões sucedidas de transgressões disciplinares eram vistas por muitos como um ato inconstitucional, mesmo que validada pelo extinto decreto 667/1969 (BRASIL, 1969a), e regia a forma como a cultura dentro da instituição se fazia, bem como forma disciplinante, como estímulo a ética militar.

O direito administrativo militar surgiu após a Constituição Federal de 1988, sendo o processo administrativo militar participante deste. Desta forma, de tal importância que se tem no âmbito jurídico, este vem se tornando cada vez mais forte, consolidando-se como um ramo próprio do direito, dotado de postulados e princípios que lhe conferem legitimidade. 
Para Costa (2011), o então direito administrativo disciplinar é um conjunto de normas e princípios pautados em lei, devidamente regulamentado, que possuem decisões oficiais que resultam em jurisprudência e doutrina sobre os processos de faltas disciplinares, no intuito de dinamizar tais procedimentos de investigação.

Há uma linha tênue que separa o direito penal militar do direito administrativo disciplinar militar, tendo em vista que o segundo corresponde a infrações administrativas. Assim, havendo forte diferença entre crime e transgressão. $\mathrm{Na}$ transgressão, a sanção administrativa disciplinar ocorre (LOPES, 2017).

[...] parece haver separado os brasileiros em dois grupos, a saber: civis e militares. Para os primeiros, só caberá prisão (i) em flagrante delito ou (ii) mediante mandado escrito e fundamentado, expedido por juiz competente. Já, em relação ao segundo grupo de brasileiros, os militares, excepcionalmente, a prisão será admitida também nos casos de (i) transgressão militar ou (ii) crime propriamente militar, definidos em lei (ROCHA, 2020, p. 1).

No entanto, a sanção disciplinar não poderia ser imposta sem o devido processo legal, cuja constituição traz "ninguém será privado da liberdade ou de seus bens sem o devido processo legal" (BRASIL, 1988).

O Procurador da República Mario Pimentel Albuquerque elucida que os princípios democráticos são excelentes em relações coordenadas - lado a lado, mas que em situações específicas de subordinação e obediência é necessário a exigência de um imperativo absoluto, que se faça em princípios morais, ou jurídicos, ou religiosos. Ele traz o exemplo da vocação religiosa em paralelo com a obediência militar em relação aos superiores (TRIBUNAL REGIONAL FEDERAL DO RIO DE JANEIRO, 2001).

Mario Pimentel Albuquerque exprime:

[...] Seu um indivíduo não está vocacionado á carreira das armas, com o despojamento que ela exige, que procure seus objetivos no amplo domínio da vida civil, onde a liberdade e a livre-iniciativa constituem virtudes [...]. (TRIBUNAL REGIONAL FEDERAL DO RIO DE JANEIRO, 2001). 
Com estas palavras, o Procurador da República Mario Pimentel Albuquerque busca trazer que o militar deve saber da exigência e do dever que seu cargo o traz, e deve estar disposto a todas sanções administrativas que tal posto repleto de hierarquia institucional evoca. Assim, a prisão administrativa, quando efetiva, acaba por ser repleta de controvérsias quanto a apoiadores e contrários com o argumento de inconstitucionalidade.

\subsection{TIPOS DE PRISÃO}

A prisão penal ou prisão de pena é decorrente de sentença de condenação transitado em julgado (LOPES, 2017). Assim, a prisão de pena representa o término do processo bem como a forma que o réu, declarado culpado, cumprirá a sentença, que é em privação de liberdade, determinada pelo juiz. Durante a proclamação da sentença, também é dito pelo juiz a duração da prisão (SIQUEIRA, 2017).

Já a prisão sem pena é aquela onde o réu aguarda a sentença judicial já privado de liberdade - ocorre quando é percebido que o acusado não pode ter liberdade e é necessária sua reclusão até o julgamento do juiz.

A prisão civil, diferente da penal, não traz a punição para infração penal (crime), mas sim a falta com obrigações civis. Neste caso, a prisão apenas se aplica ao caso de não pagamento de pensão alimentícia (SIQUEIRA, 2017).

A prisão militar vem especificamente descrita no direito penal militar. A Constituição Federal de 1988 definiu, em seu artigo 5o, a prisão militar em virtude de transgressões militares ou crime propriamente militar; enquanto no Código Penal Militar (BRASIL, 1969b), este é descrito em dois tipos: crimes militares em tempo de paz, e crimes militares em tempos de guerra.

Neves e Streifinger (2014) afirmam que o delito militar é todo aquele que é oriundo da vida militar. Enquanto, para Lima (2015), crime propriamente militar só pode ser praticado por militar e da natureza do objeto danificado, podendo ser: serviço, disciplina, administração ou economia militar. 
Siqueira (2017), posiciona que crime militar próprio é o previsto no Código Penal Militar, e não possui correspondência ou paralelo ao código penal comum - assim, o mesmo crime não deve existir no código militar nem no código penal, que pune civil. Assim, se existir uma correspondência, será definido de modo diverso. No entanto, contravenção penal cometida não existe responsabilidade civil ou militar, já que uma forma não exclui outra.

Já a prisão disciplinar tem cunho administrativo e era regulamentada tendo por base - Regulamento Disciplinar do Exército, resultando em Decreto espedidos pelos respectivos Governadores Estaduais aos seus militares, outorgando a autoridades militares superiores o poder de punir o agente público militar subordinado quando este cometesse uma transgressão militar. Foi justamente este tipo de prisão que foi extinta por Lei em 2019, e motivou algumas controvérsias entre políticos, militares e agentes de direito.

\subsection{DA PRISÃO ADMINISTRATIVA}

Lima (2015, p. 842) define a prisão administrativa como "espécie de prisão decretada por autoridade administrativa com o objetivo de compelir alguém a cumprir um dever de delito público". No entanto, é notório que ocorre alguns abusos por parte administrativa, motivo da implementação da Lei 13.967/2019.

A medida se insere dentro do poder disciplinar que é comum às instituições militares e, do dever de ofício que as autoridades militares que presenciam ou tomam conhecimento de infração disciplinar de natureza grave têm, de intervir prontamente e de forma enérgica. (ASSIS, 2009, p.159).

Assim, a prisão administrativa disciplinar é vista, segundo Lima (2015), como uma obrigação do punido militar permanecer em local específico para tal.

No entanto, com a Carta Magna, a prisão trazida no artigo 5, inciso LXI, já citado neste trabalho, afirma " [...] LXI - ninguém será preso senão em flagrante delito ou por ordem escrita e fundamentada de autoridade judiciária competente, salvo nos casos de 
transgressão militar ou crime propriamente militar, definidos em lei" (BRASIL, 1988) Constituição Federativa, como já mencionado.

\subsection{A TRANSGRESSÃO DISCIPLINAR MILITAR}

A transgressão disciplinar militar pode ser considerada toda ação ou omissão praticada por militar que viole os preceitos da ética e os valores militares; ainda, também, que contrarie os deveres e obrigações a que este está submetido. Vale entender que a transgressão não pode ser tipificada como crime ou contravenção penal, assim, passível de ação administrativa disciplinar (SIQUEIRA, 2017).

Qualquer cidadão está sujeito a praticar um ato ilícito, até mesmo um Policial Militar, pois mesmo tendo conhecimento das leis, não está isento de errar. A infração não se faz presente apenas em atos de um cidadão comum. Sendo assim, o Policial não está acima da Lei. A punição advinda de atos ilícitos é necessária para que, através de sua realização e compreensão de sua existência, outros sujeitos não os pratiquem.

Conforme Siqueira (2017), a transgressão disciplinar por definição não é um crime, mas uma contravenção que fere os valores da vida militar, tais como qualquer infração dos princípios da ética que contrarie os deveres e obrigações militares, sendo em manifestação elementar e simples, e toda omissão ou ação adversa as cláusulas estatuídas em lei, regulamentos, normas ou disposições.

Neste sentido, a presunção da inocência dentro do processo disciplinar administrativo militar possui um desdobramento diferente do encontrado no Direito Penal. Enquanto o Código Penal pensa em presunção da inocência em primeiro plano e aplica o princípio da proporcionalidade à punição do delito, o Código Militar traz critérios de disciplina e respeito a hierarquia em primeiro lugar.

\subsubsection{ELEMENTOS DA TRANSGRESSÃO DISCIPLINAR}

A transgressão disciplinar não é considerada um crime propriamente dito, é vista como um desrespeito aos princípios militares e só é considerada como tal quando alguns elementos se fazem presentes para sua configuração como: dolo, prática consistente, 
a não ser que o tipo queira punir a conduta culposa, imprudência, negligência ou imperícia (BRASIL, 2002).

Os princípios da transgressão disciplinar são semelhantes aos instrumentos do crime que podem ser classificados como típicos e antijurídico, além de serem fatores indispensáveis para que se evite a ocorrência de excessos. Tal fenômeno podem acontecer em julgamentos administrativos devido ao fato da ingenuidade não ter o mesmo desenvolvimento do Direito Penal. Dito isso, de maneira imprescindível, a preparação da doutrina da transgressão disciplinar é necessária para que haja uma busca de ocupação dos títulos destacados na Constituição Federal (BRASIL, 1988).

O Art. 18 do Decreto № 4.346 de 26 de agosto de 2002 (BRASIL, 2002) discorre acerca dos motivos que justificam a transgressão disciplinar. De maneira relevante esse artigo é analisado, pois possibilita a ação judiciária por parte do militar caso punido, esclarecendo o motivo que justificasse efetivamente a culpa do militar pela acusação de transgressão.

A prática do ato disciplinar não quer dizer basicamente a determinação de uma pena ao militar. A transgressão pode estar justificada dentro das normas disciplinares. O Código Penal e o Código Penal Militar, preveem a falta de necessidade de punição para o militar que comprovar que a acusação de transgressão imposta a ele teve uma justificativa, impedindo assim, a punição, ou seja, durante sua jornada de trabalho, agindo em favor da garantia da segurança, ocorrendo uma transgressão disciplinar que tenha a possibilidade de ser justificada baseada em uma das excludentes apresentadas, estará livre da punição imputada pela autoridade administrativa militar (SIQUEIRA, 2017, p. 22).

Assim, a autoridade se torna obrigado a reconhecer se a justificativa apresentada está dentro do enquadrado pela Lei, visto que na transgressão disciplinar militar não existe a possibilidade de poder arbitrário.

\subsubsection{DIFERENÇA ENTRE TRANSGRESSÃO MILITAR E CRIME MILITAR}

São exigidos, tantos do Bombeiro Militar quanto do Policial Militar, que suas ações estejam de acordo com os princípios militares de rigorosa disciplina, pois o contrário, 
o trabalho possuirá menos qualidade e comprometerá a repartição da qual faz parte (BRASIL, 2002).

Assim, a transgressão ou também contravenção disciplinar, constitui, conforme Lima (2007, p. 1).

Contravenção ou transgressão disciplinar é toda ação ou omissão que não constitua crime militar, ofensiva à ética, às obrigações ou aos deveres militares, ou, ainda que a afete a honra pessoal, o pundonor militar, o decoro da classe, e, como tal, é classificada pelos regulamentos disciplinares das Forças Armadas.

Assim, entende-se que apesar do Direito Penal Militar e o Direito Disciplinar serem diferentes, possuem o mesmo objetivo, que é a prevenção e punição de práticas ilícitas. Assim, o comportamento do militar apenas será abordado como transgressão disciplinar ou crime propriamente militar se estiverem enquadradas dentro do que diz as respectivas legislações, sem suposições ou interpretações.

\subsection{APLICAÇÃO DA LEI № 13.967/2019}

A Lei 13.967 de 2019, enfim, entrou em vigor após 5 anos de tramitação e discursão. Esta prevê que os Policiais Militares e Bombeiros Militares apenas podem sofrer punições disciplinares, que estão previstas nos respectivos estatutos, como suspensões e multas.

A prisão preventiva somente será determinada quando não for cabível a sua substituição por outra medida cautelar, e o não cabimento da substituição por outra medida cautelar deverá ser justificado de forma fundamentada nos elementos presentes do caso concreto, de forma individualizada (BRASIL, 2019).

Por se tratar de uma legislação que passou a vigorar a partir da publicação e por trazer a extinção de uma punição, aqueles militares que se encontravam em cumprimento dessa punição antes da publicação da norma foram recepcionados por tal, neste contexto, exsurge com inegável força o princípio da retroação da lei mais benéfica, de que trata 0 artigo $5^{\circ}, \mathrm{XL}$, da Constituição Federal, quando assevera que a lei penal não retroagirá, salvo para beneficiar o réu. Como exemplo, podemos citar uma 
decisão na Vara da Auditoria da Justiça Militar Cível de Curitiba/PR, que concedia medida liminar para a imediata liberdade do policial militar que havia sido colocado sob punição disciplinar privativa de liberdade após a publicação da lei em 2019 (TRIBUNAL DA JUSTIÇA DO PARANÁ, 2020).

Com a publicação da Lei 13.967/2019, a possibilidade de prisão por infração disciplinar militar foi extinta do ordenamento jurídico pátrio. Assim, tonaram-se ilegais as prisões de militares em decorrência de decisões administrativas. É o caso dos presentes autos, em que o Paciente se encontra recluso por força de decisão administrativa proferida pelo Comandante da PMPR. Mesmo que o art. $3^{\circ}$ da nova Lei preconize que os "Estados e o Distrito Federal têm o prazo de doze meses para regulamentar e implementar esta Lei", a necessidade de edição de leis e atos normativos complementares não pode ser oposta aos que se encontram reclusos por força de medida extirpada do ordenamento jurídico. Eventual condição de eficácia da Lei válida e vigente não obsta a imediata colocação em liberdade daqueles que estão submetidos à medida hoje considerada ilegal (TRIBUNAL DE JUSTIÇA DO PARANÁ, 2020).

Assim, com essa alteração posta o propósito é que haja outras formas de punição ao militar transgressor diferente da prisão, e ainda conforme estabelecido os Estados e Distrito Federal deverão dentro do prazo de 12 (doze) meses planejar e publicar um Código de Ética e Disciplina Militar com base nos princípios elencados e alterados pela Lei 13.967/2019 no art.18 do Decreto-lei 667/69. Nesse sentido para melhor elaboração dos CED e observância dos princípios trazidos pela alteração da lei o art.319 do Código de Processo Penal que traz o rol incisos de medidas cautelares diferentes da prisão.

\subsection{ESTATUTOS DISCIPLINARES}

Como a legislação que regula as transgressões disciplinares apenas deve se ter como base o Regulamento Disciplinar do Exército, e também como cada ente federativo possui sua autonomia, cada Estado editou seu Decreto que passou a se chamar Estatuto dos Militares, onde organizou e classificou as transgressões e suas punições entre outros assuntos. Nesses mais diversos Estatutos Disciplinares existiam a previsão de recolhimento do transgressor, de maneira que ele fosse preso em função 
de sanção disciplinar. E, em outros, também era permitido, sem a função de punição e, quando necessário ao andamento das investigações para a apuração ou preservação da ordem militar, principalmente quando o militar se mostre agressivo ou sob uso de álcool ou entorpecentes (SÃO PAULO, 2001).

A prisão disciplinar faz parte das punições a que o Militar estar sujeito, por exemplo, conforme o Regulamento Disciplinar da Polícia Militar de Goiás (GOIÁS,1996):

Art. 20 - As punições disciplinares a que estão sujeitos os policiais militares, segundo a classificação resultante do julgamento das transgressões, são as seguintes:

I - Advertência;

II - Repreensão;

III - Detenção;

IV - Prisão;

V - Transferência a bem da disciplina;

VI - Licenciamento a bem da disciplina;

VII - exclusão a bem da disciplina.

Anterior a fase da aplicação da punição tem-se a apuração do fato chamada sindicância que, de certa forma, é respeitado o devido processo legal, pois não possui a finalidade repressiva em caráter de punição. O princípio constitucional de presunção da inocência é respeitado, enquanto foca-se no bom andamento da investigação, posterior a essa fase que se encontrava o problema, pois com a apuração realizada e atribuído responsabilidade ao transgressor, a punição disciplinar se daria conforme entendimento dos superiores incluindo a prisão.

\section{CONVERSÃO DA PRISÃO ADMINISTRATIVA EM OUTRAS PENALIDADES}

Como citado no início, alguns Estados, antes mesmo da Lei 13.967/2019 que extinguiu a pena disciplinar de prisão, já haviam sido pioneiros em relação a mudança 
da prisão administrativa em outras penalidades, tais como o Estado da Paraíba há três anos antes, que declarou extinta a prisão disciplinar através do Decreto no 36.924/2016 (PARAÍBA, 2016).

Art. 10 Fica vedado o cumprimento de punição disciplinar com cerceamento da liberdade no âmbito da Polícia Militar da Paraíba. Art. $2^{\circ}$ As punições disciplinares de prisão e detenção serão adotadas apenas para fins de assentamentos e classificação de comportamento nas fichas funcionais (PARAÍBA, 2016).

Tal decreto impede excessos por parte de Comandantes, bem como pena de prisão em casos mais simples. As transgressões disciplinares mais simples não serão punidas com pena de privação de liberdade, e não impede que ocorram outras punições.

Também abre oportunidade para diferentes entendimentos a respeito de punições administrativas para Policiais Militares, servindo como base para possíveis mudanças na forma de fazer com que o militar (Bombeiro ou Policial) arrependa dos seus atos e pague a instância militar o que fez.

A Lei 13.967 de 2019 (BRASIL, 2019) permite novas formas de punição administrativa para transgressões disciplinares. A exemplo da Polícia Militar de Pernambuco, que não possui espaços para a restrição de liberdade, esta aprovação foi substancial. Além disso, a redução ou extinção da liberdade de realizar horas extras pode se mostrar como uma excelente forma de punição administrativa. Isto é possível porque há um projeto que possibilita a prestação de horas extras remuneradas nos dias de folgas para os Militares, possibilitando um acréscimo na renda mensal do militar (PERNAMBUCO, 1999), ou também, como forma de punição, sem o acréscimo salarial ao militar, mas reforçando o policiamento.

Enquanto nas infrações mais leves não se vê a necessidade de afastamento do mesmo do serviço de rua. Como alternativa, penas como serviço comunitário ou formação compulsória podem ser eficazes para a recuperação do militar, bem como dada a chance de arrependimento a este, ao refletir sobre suas ações. Ainda, é possível o militar participar de medidas educativas dentro de alguma entidade 
educacional, onde poderia realizar palestras entre outras atividades socioculturais relevantes para a região que está lotado (SIQUEIRA, 2017).

Suspensão, um método previsto em lei como punição, pode ocorrer para delitos mais graves. A suspensão pode ocorrer também através da proibição de mudança de patenteou graduação, após trânsito em julgado, do devido processo.

A Polícia Militar de Minas Gerais, quando publicou seu Código de Ética e Disciplina (MINAS GERAIS, 2002), elucida que a sanção disciplinar tenha caráter preventivo e educativo, extinguindo a pena de prisão quando tipificou as transgressões disciplinares.

Art. 24 - Conforme a natureza, a graduação e as circunstâncias da transgressão, serão aplicáveis as seguintes sanções disciplinares:

I - Advertência;

II - Repreensão;

III - prestação de serviços de natureza preferencialmente operacional, correspondente a um turno de serviço operacional, que não exceda a oito horas;

IV - Suspensão, de até 10 dias;

V - Reforma disciplinar compulsória;

VI - Demissão;

VII - Perda do posto, patente ou graduação do militar da reserva (MINAS GERAIS, 2002).

O Código Penal Militar não estabelece pena de Multa. Mas, diante das alterações da Lei n. 13.967 em 2019, vê-se um cenário favorável à previsão de aplicação desta como penalidade alternativa à da prisão administrativa.

No direito administrativo, a penalidade disciplinar tem por finalidade coibir e prevenir o cometimento de ilícitos administrativos praticados por servidores que faltaram com a ética, de caráter intimidador e educador, demonstrando a administração pública o 
interesse em manter a normalidade e as boas práticas no serviço administrativo (LOPES, 2017).

O artigo 49 do Código de Direito Penal Brasileiro define pena de multa como um pagamento a fundo penitenciário, com quantia fixa na sentença e calculada em diasmulta (BRASIL, 1940).

Cunha (2017, p. 495) entende que pena de multa se define em "[...] espécie de sanção penal patrimonial, consistente na obrigação imposta ao sentenciado de pagar ao fundo penitenciário determinado valor em dinheiro".

Prado (2004) prossegue com o raciocínio, entendendo que pena não é tributo, e consiste na imposição ao condenado uma obrigação de pagar ao fundo penitenciário uma quantidade em dinheiro determinada em julgamento, de maneira que atinja o patrimônio do condenado.

Diante da não-existência da prisão disciplinar, ao buscar o direito penal comum, entende-se que a multa pode ser descontada do salário do condenado de forma parcelada, ressalvando-se que não deva incidir sobre os recursos indispensáveis ao sustento do condenado e da sua família (BRASIL, 1940).

Ainda, quando for conveniente ao serviço, conforme a Lei 8.112/1990 (BRASIL, 1990), a suspensão também poderá ser convertida em multa em base de $50 \%$ da remuneração por dia de remuneração, assim, o servidor se torna obrigado a permanecer em serviço.

\section{CONSIDERAÇÕES FINAIS}

A promulgação da Lei № 13.967 permite que a carreira militar seja pautada nos princípios constitucionais da dignidade da pessoa humana, legalidade, presunção da inocência, devido processo legal, contraditório, ampla defesa, razoabilidade e proporcionalidade, ainda vendado a medida de restrição de liberdade. Neste sentido, entende-se que na carreira Militar, mesmo valorada no valor elevado da missão e com "risco da própria vida", baseado na hierarquia e disciplina, a vida do militar enquanto 
serviço é passível de erros e, quando cometidos, que sejam apurados e apenados nos ditames da lei.

Seria fácil apenas sugerir de maneira singela que as penas de restrições à liberdade sejam suprimidas, no entanto o grande desafio está na realização deste ato sem que seja deixado de lado a preocupação com o reforço da hierarquia e disciplina. Fato este apresentado no presente projeto

Neste contexto, propõe-se adjunto a alteração do rol punitivo, uma revisão geral do Código Disciplinar, a fim de adequar os tipos ali estabelecido à realidade cotidiana, diante dos princípios da mutação normativa, além da abolição das penas de detenção e prisão, restritivas a liberdade em essência.

Em vista deste trabalho, atualmente, dentro da gama de transgressões disciplinares, algumas podem ser reprimidas por meio de uma simples admoestação, verbal ou escrita, ou como citado anteriormente como sugestão o rol de medidas cautelares do CPP ou outras medidas comumente usadas por outros órgãos com a finalidade de punitiva e também educacional para o infrator.

A adoção dessas medidas trará grandes benefícios ao sistema de controle de disciplina, de modo a restaurar a sua eficácia, proporcionando um ambiente melhor de trabalho aos militares estaduais, o que reflete na qualidade dos serviços prestados junto à Comunidade e público alvo, apresentando maior benefício a todo o mecanismo estadual de defesa social.

\section{REFERÊNCIAS}

ASSIS, Jorge César de. Curso de Direito Disciplinar Militar: da simples transgressão ao processo administrativo. 2.ed. Curitiba: Juruá, 2009.

BRASIL. Presidência da República. Decreto-Lei no 667, de 2 de julho de 1969. Reorganiza as Polícias Militares e os Corpos de Bombeiros Militares dos Estados, dos Território e do Distrito Federal, e dá outras providências. Brasília, DF: Presidência da 
República, 1969a.Disponível em: http://www.planalto.gov.br/ccivil_03/DecretoLei/Del0667.htm. Acesso em: 7 fev. 2020.

BRASIL. Presidência da República. Decreto-Lei no 1.001, de 21 de outubro de 1969b. Código Militar Penal. Brasília, DF: Presidência da República, 1969a. Disponível em: http://www.planalto.gov.br/ccivil_03/decreto-lei/del1001.htm. Acesso em: 11 fev. 2020.

BRASIL. Presidência da República. Constituição da República Federativa do Brasil de 1988. Brasília, DF: Presidência da República, [2019]. Disponível em: http://www.planalto.gov.br/ccivil_03/constituicao/constituicao.htm. Acesso em: 8 fev. 2020.

BRASIL. Presidência da República. Decreto-Lei no 2.848, de 7 de dezembro de 1940. Código Penal. Brasília, DF: Presidência da República, 1940. Disponível em: http://www.planalto.gov.br/ccivil_03/decreto-lei/del2848compilado.htm. Acesso em: 11 fev. 2020.

BRASIL. Presidência da República. Lei no 13.967, de 26 de dezembro de 2019. Altera o art. 18 do Decreto-Lei oㅡ 667, de 2 de julho de 1969, para extinguir a pena de prisão disciplinar para as polícias militares e os corpos de bombeiros militares dos Estados, dos Territórios e do Distrito Federal, e dá outras providências. Brasília, DF: Presidência da República, 2019. Disponível em: http://www.planalto.gov.br/ccivil_03/_ato2019-2022/2019/lei/L13967.htm. Acesso em: 7 fev. 2020.

BRASIL. Presidência da República. Lei no 12.403, de 4 de maio de 2011. Altera dispositivos do Decreto-Lei no 3.689, de 3 de outubro de 1941 - Código de Processo Penal, relativos à prisão processual, fiança, liberdade provisória, demais medidas cautelares, e dá outras providências. Brasília, DF: Presidência da República, 2011. Disponível em: http://www.planalto.gov.br/ccivil_03/_Ato20112014/2011/Lei/L12403.htm. Acesso em: 11 fev. 2020. 
BRASIL. Presidência da República. Decreto no 4.346, de 26 de agosto de 2002. Aprova o Regulamento Disciplinar do Exército (R-4) e dá outras providências. Brasília, DF: Presidência da República, 2002. Disponível em: http://www.planalto.gov.br/ccivil_03/decreto/2002/d4346.htm. Acesso em 9 fev. 2020.

BRASIL. Presidência da República. Decreto 90.608 de 04 de dezembro de 1984. Brasília, DF: Presidência da República, 1984. Aprova o Regulamento Disciplinar do Exército (R-4) e dá outras providências. Revogado pelo Decreto no 4.346, de 26.8.2002. Brasília, DF: Presidência da República, 1984. Disponível em: http://www.planalto.gov.br/ccivil_03/decreto/antigos/d90608.htm. Acesso em: 8 fev. 2020.

CÂMARA LEGISLATIVA FEDERAL (Brasil). Projeto de Lei 7645/2014. Altera o art. 18 do Decreto-Lei no 667, de 2 de julho de 1969, que extingue a pena de prisão disciplinar para as polícias militares e os corpos de bombeiros militares, dos estados, dos territórios e do Distrito Federal, e dá outras providências. Brasília, DF: Câmara Legislativa Federal, $2014 . \quad$ Disponível em: https://www.camara.gov.br/proposicoesWeb/fichadetramitacao?idProposicao=61789 8. Acesso em: 10 fev. 2020.

COSTA, José Armando da. Processo administrativo disciplinar: teoria e prática. 6 . ed. Rio de Janeiro: Forense, 2011.

CUNHA, Rogério Sanches. Manual de direito penal: Parte Geral. 5. ed. Salvador: Juspodivm, 2017.

GIL, Antonio Carlos. Métodos e técnicas da pesquisa social. 6.ed. São Paulo: Atlas, 2008.

GOIÁS (Brasil). Governo do Estado de Goiás. Decreto n.․․ 4.717 de 7 de outubro de 1996. Aprova o Regulamento Disciplinar da Polícia Militar do Estado de Goiás RDPM-GO.. Goiânia: Governo do Estado de Goiás, 1996. Disponível em: http://www.gabinetecivil.go.gov.br/pagina_decretos.php?id=5086. Acesso em: 12 fev. 2020. 
LIMA, Renato Brasileiro de. Manual de processo penal. 3.ed. Salvador: JusPodivm, 2015.

LIMA, Antonio da Silva. Prisão Administrativa Militar por Transgressão Disciplinar. Jusmilitaris, 2007.

Disponível

em: http://jusmilitaris.com.br/sistema/arquivos/doutrinas/prisaoadmmilitar.pdf. Acesso em: 9 fev. 2020.

LOPES, Adriano Antônio dos Santos. Da prisão administrativa e sua conversão em multa na polícia militar de Goiás. Trabalho de Conclusão de Curso (Pós-Graduação em Gerenciamento de Segurança Pública) - Universidade Estadual de Goiás; Secretaria da Segurança Pública, São Paulo, 2017. Disponível em: https://acervodigital.ssp.go.gov.br/pmgo/bitstream/123456789/431/1/Da\%20Pris\%C3 \%A30\%20Administrativa\%20e\%20sua\%20Convers\%C3\%A30\%20em\%20

Multa\%20na\%20Pol\%C3\%ADcia\%20Militar\%20de\%20Goi\%C3\%A1s\%20\%20Adrianio\%20Ant\%C3\%B4nio\%20dos\%20Santos\%20Lopes.pdf. Acesso em: 10 fev. 2020.

MINAS GERAIS (Brasil). Assembleia Legislativa do Estado de Minais Gerais. Lei no 14.310, de 19 de junho de 2002. Dispõe sobre o Código de Ética e Disciplina dos Militares do Estado de Minas Gerais. Belo Horizonte: Assembleia Legislativa do Estado de Minas Gerais, 2002. Disponível em: https://www.almg.gov.br/consulte/legislacao/completa/completa.html?num=14310\&a no=2002\&tipo=LEl. Acesso em: 12 fev. 2020.

NEVES, Cícero Robson Coimbra; STREIFINGER, Marcello. Manual de Direito Penal Militar. 4.ed. São Paulo: Saraiva, 2014.

PERNAMBUCO (Brasil). Governo do Estado de Pernambuco. Decreto no 21.858, de 25 de novembro de 1999. Institui o Programa Jornada Extra de Segurança, e dá outras providências. Recife: Governo do Estado de Pernambuco, 1999. Disponível em: 
http://www.portais.pe.gov.br/c/document_library/get_file?p_I_id=13043\&folderld=700 87\&name=DLFE-27305.pdf. Acesso em: 11 fev. 2020.

PRADO, Luiz Regis. Curso de Direito Penal Brasileiro. São Paulo: Editora RT, 2004.

ROCHA, Abelardo Julio da. Da extinção das sanções disciplinares militares privativas de liberdade. Jus, jan. 2020. Disponível em: https:/jus.com.br/artigos/78875/daextincao-das-sancoes-disciplinares-militares-privativas-de-liberdade. Acesso em: 7 fev. 2020.

TRIBUNAL REGIONAL FEDERAL DO RIO DE JANEIRO. Parecer lançado nos autos do HC 2.217/RJ - TRF/2a Região - Rel. Des. Federal Sérgio Correa Feltrin - j. Rio de Janeiro: Tribunal Regional Federal do Rio de Janeiro, 25 abr. 2001.

TRIBUNAL DA JUSTIÇA DO PARANÁ (Brasil). Poder Judiciário do Paraná. Habeas Corpus Cível. Liminar. Autos n ‥ 0000020-33.2020.8.16.0013. Curitiba, 3 jan. 2020. Disponível em: https://www.migalhas.com.br/arquivos/2020/1/6DBE3FC1C8EE33_decisaopm.p df. Acesso em: 9 fev. 2020.

SÃO PAULO (Brasil). Assembleia Legislativa do Estado de São Paulo. Lei complementar no 893, de 9 de março de 2001. Institui o Regulamento Disciplinar da Polícia Militar. São Paulo: Assembleia Legislativa do Estado de São Paulo, [2002]. Disponível em: https://www.al.sp.gov.br/repositorio/legislacao/lei.complementar/2001/lei.complement ar-893-09.03.2001.html. Acesso em: 11 fev. 2020.

SIQUEIRA, Rivaldo César Ferreira de. A privação de liberdade na prisão disciplinar do militar estadual de Pernambuco: uma breve reflexão sobre as possibilidades de mudança. Monografia (Graduação em Direito) - Faculdade Damas da Instrução Cristã, Recife, 2017. Disponível em: https://www.faculdadedamas.edu.br/revistafd/index.php/academico/article/viewFile/7 86/644. Acesso em: 12 fev. 2020. 
Enviado: Setembro, 2020.

Aprovado: Outubro, 2020. 